Elemente und Ephemeride des von Prof. A. W innecke in Strassburg am 5. April entdeckten Cometen,

berechnet von Dr. J. Holetschek.

Circular der kaiserlichen Akademie der Wissenschaft in Wien.

Bis zum Scllusse der Rechnung waren die folgenden Beobachtungen eingelaufen:
1. Strassburg
1877 mttl. Ortszeit
app. a $\mathbb{E}$
app. $\delta$ \& Beobachter
2. Kremsmünster

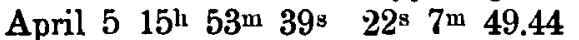
$+14^{0} 54^{\prime} 15^{\prime \prime} .4$ Winnecke
3. Mailand
4. Wien
5.
$\begin{array}{lllll}6 & 15 & 32 & 27\end{array}$
$22 \quad 8 \quad 33.35$
+16128.6 Strasser.
6. Pola

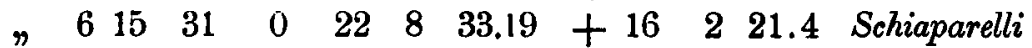
$\Rightarrow \begin{array}{lllllllll}715 & 26 & 52 & 22 & 9 & 20.39 & + \\ 77 & 12 & 9.3 \text { Weiss }\end{array}$
$7 \quad 716 \quad 8 \quad 40 \quad 229922.39+171411.8$ A. Palisa
$\begin{array}{llllllllllll}7 & 15 & 2 & 28 & 22 & 9 & 20.06 & + & 17 & 11 & 28.8 & \text { J. Palisa }\end{array}$

Die Beobachtungen 1, 2 und das Mittel aus 4 und 5 führen auf das folgende Elementensystem:

$T=1877$ April 14.3283 mittl. Berl. Zeit.

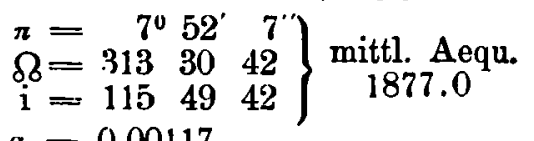

$\log q=0.00117$.

Darstellung der mittleren Beobachtung (B.-R.):

$$
\begin{aligned}
\mathrm{d} 2 \cos \beta & =-3 \\
\mathrm{~d} \beta & =+2 .
\end{aligned}
$$

1877

\begin{tabular}{rrrrr} 
April & 9 & \multicolumn{2}{c}{$\alpha$} \\
& $22 \mathrm{l}$ & \multicolumn{1}{c}{$10 \mathrm{nu}$} & อ3 \\
13 & 22 & 14 & 44 \\
17 & 22 & 19 & 25 \\
& 21 & 22 & 25 & 20 \\
& 25 & 22 & 33 & 10 \\
& 29 & 22 & 44 & 0 \\
Mai & 3 & 23 & 0 & 4 \\
& 7 & 23 & 26 & 20 \\
11 & 0 & 16 & 1
\end{tabular}

Ephemeride für $12^{\mathrm{h}}$ Berliner Zeit.

\begin{tabular}{rrccc}
\multicolumn{1}{c}{$\delta$} & $\log \Delta$ & $\log \mathrm{r}$ & Lichtstärke \\
$+19^{0}$ & $31: 0$ & 0.1459 & 0.0026 & 1.13 \\
22 & 53.8 & 0.1216 & 0.0012 & 1.27 \\
30 & 53.6 & 0.0984 & 0.0018 & 1.41 \\
37 & 31.3 & 0.0774 & 0.0044 & 154 \\
44 & 44.1 & 0.0601 & 0.0090 & 1.63 \\
52 & 24.6 & 0.0481 & 0.0153 & 1.67 \\
60 & 18.8 & 0.0426 & 0.0232 & 1.65 \\
68 & 6.1 & 0.0442 & 0.0326 & 1.57 \\
+75 & 14.1 & 0.0529 & 0.0431 & 1.44
\end{tabular}

Der Lichtstärke liegt als Einheit die Lichtstärke bei der Entdeckung zu Grunde.

\title{
Beobachtung des Cometen c 1877 (Borrelly).
}

$$
\begin{aligned}
& \text { m. Z. Kiel. " \& } \\
& \text { 1877 April 16. 10 } 30^{\mathrm{h}} \text { m } 478.4+56^{\circ} 32^{\prime} 39^{\prime \prime} .7
\end{aligned}
$$

$\begin{array}{lllllll}11 & 7 & 43.6 & 1^{\mathrm{ll}} & 23^{\mathrm{m}} & 15^{\mathrm{s}} .06\end{array}$

Mittlerer Ort des Vergl. für 1877.0

Kiel, 1877 April 17.

Lal. 2465. $\because=1^{\mathrm{h}} 16^{\mathrm{m}} 40^{\mathrm{s}} .22 \quad \delta=+56^{\circ} 33^{\prime} 23^{\prime \prime} .0$

In h a $1 \mathrm{t}$ :

Zu Nr. 2125. Powalky. Reduction von Lacailles Bestimmungen südlicher Sterne durch correspond. Höhen, am Cap. (Schluss.) 193. W. Valentiner. Beobachtung des Cometen b 1877 (Winnecke) 203. - Entdeckung eines Cometen (c 1877). 205. C. F. W. Pters. Beobachtung des Cometen b 1877 (Winnecke) 205. - W. Klinkerfues. Beobachtung des Cometen Winnecke auf derSternwarte zu Göttingen. 205. - V. Knorre. Beobachtung des Cometen b 1877 205. - Beobachtungen der Cometen b und c 1877 205. - Dr. F. Holetschek. Elemente und Ephemeride des von Prof, A. Winnecke in Strassburg am 5. April entdeckten Cometen 207. $-C . F . W$. Peters. Beobachtung des Cometen c 1877. (Borrelly) 207. 